\title{
EDUCACIÓN
}

\section{Camino a Delfos. Orientación vocacional: proceso de toma de decisiones con aplicación del autoinforme}

\author{
Marlyn Noemí López Rojas', Ninfa González Orrego², Inés Herminia \\ Quintana Ramos ${ }^{3}$, Oscar Misael Sosa Gómez ${ }^{4}$
}

\section{Resumen}

Introducción: El trabajo se centra en la toma decisiones, introduciendo la aplicación de autoinformes con el doble propósito de ofrecer a los alumnos un recurso de autoconocimiento y, al mismo tiempo, determinar la eficacia del uso del autoinforme en el proceso de elección vocacional.

Objetivo: Validar el uso de autoinformes como recurso de autoconocimiento para los alumnos y como estrategia de acompañamiento en la orientación vocacional para los docentes.

Material y Método: Se procedió a la selección de cuestionarios y escalas que abordan cinco aspectos que intervienen en el proceso de la toma de decisiones. Los mismos han sido adaptados al contexto paraguayo para su aplicación en instituciones públicas y privadas a alumnos de la modalidad de bachillerato científico y técnico, con el fin de realizar un análisis descriptivo-correlacional de los datos obtenidos.

Resultados: En el espectro de valores, para las mujeres impera el valor del conocimiento; los varones, en cambio, han optado por los valores de la solidaridad y el bienestar económico. A nivel general, los valores predominantes son el conocimiento, la solidaridad y la satisfacción personal; en contrapartida, al final de la escala quedaron el poder, el prestigio social y sin puntuación alguna la creatividad. En cuanto al rendimiento académico, la diferencia entre géneros es sutil con una leve superioridad de los varones sobre las mujeres. Sobre las preferencias académicas se puede realizar una diferenciación más marcada: los varones tienden a escoger áreas instrumentales; las mujeres, en cambio son obtienen mejores resultados en humanidades. La variable señalada como factor decisivo en el rendimiento es el esfuerzo, por lo que la responsabilidad de éxito o fracaso recae en el estudiante. En la identificación de capacidades y destrezas la mayor puntuación recayó en la

1. Universidad Nacional de Asunción. Facultad de Filosofía.

2. Universidad Centro Médico Bautista.

3. Colegio Nacional San Lorenzo.

4. Universidad Iberoamericana. Departamento de Relaciones Internacionales e Investigación.

Trabajo presentado en la asignatura de Diagnóstico y Orientación académico profesional en Máster Universitario en Formación Internacional Especializada del Profesorado. Universidad Complutense de Madrid.

E-mail: marlynnoemi.lopez@hotmail.com

DOI: 10.26885/rcei.foro.2018.54 


\section{Camino a Delfos. Orientación vocacional. López Rojas et al.}

creatividad, lo cual llama la atención al no recibir puntuación alguna en la escala de valores, otras habilidades predominantes son el ser detallista y la habilidad para planificar y dirigir. En contra partida, los estudiantes manifiestan no poseer habilidades para influir, persuadir y las manipulativas en grados muy inferiores. El factor socioeconómico influye directamente en la elección vocacional, se evidencia que en los alumnos del sector público predomina la incertidumbre de continuar con los estudios, a diferencia de los alumnos del sector privado. La disponibilidad de recursos y la implicancia o no de desplazamiento tienen menor relevancia para alumnos del sector privado que para los del sector público. En ambos sectores, la elección vocacional no está adscripta al deseo o imposición de los padres. La mayoría de los estudiantes considera estar cursando la modalidad de bachillerato que corresponde con sus preferencias, aptitudes y destrezas. Conclusiones: La historia académica y la continuidad del estudio son consistentes. Los jóvenes perciben que tienen capacidades o características personales para la opción de bachillerato elegido. Sin embargo, la variedad de instrumentos aplicados permite entrever la falta de una reflexión más profunda acerca de dicha relación, como en el caso de la creatividad y el rendimiento escolar en relación a áreas académicas preferentes. Se revela, entonces, la necesidad de adaptar y/o mejorar el proceso de orientación vocacional para que los jóvenes cuenten con suficientes elementos durante el proceso de toma de decisiones, el uso de autoinformes como recurso de autoconocimiento y de comprensión del contexto es adecuado por la diversidad de aspectos que permite trabajar y que el estudiante mismo puede confrontar con el debido acompañamiento.

Palabras clave: autoinforme, orientación vocacional, toma de decisiones.

\section{Referencias}

Álvarez, M., Fernández, A., Fernández, R., Flaquer, T., Moncosi, J., Sullá, T. (1991). Presupuestos del modelo de Orientación vocacional. Su implantación en el ámbito escolar. En Antúnez, (Ed.). La orientación vocacional a través del curriculum y la tutoría. Una propuesta para la etapa de 12 a 16 años (pp. 15-21). Barcelona, España: Graó.

Denzin, N., Yvonna, L. (2015) Métodos de recolección y análisis de datos. Barcelona, España: Gedisa.

Madrigal, A., Navarro, E., Parras, A., Redondo, S., Vale, P. (2009). Orientación académicoprofesional. En A. Parras \& M. Grañeras (Ed.), Orientación educativa: fundamentos teóricos, modelos institucionales y nuevas perspectivas (pp.225-281). Madrid, España: Ministerio de Educación.

Rodríguez, A., Sánchez, M. (2003). Principios, fundamentos y necesidad de la Orientación profesional. En M. L. Rodríguez (Ed.), Orientación profesional. Un proceso a lo largo de la vida (pp. 49-62). Madrid, España: Dykinson.

Valls, F. (1998). Enfoques de la Orientación Profesional. En F. Valls (Ed.), Fundamentos de Orientación profesional para psicopedagogos (pp. 105-131). Almería, España: Universidad de Almería. 